\title{
TRABALHO E CONTROLE DE QUALIDADE NA INDÚSTRIA DE ALIMENTOS
}

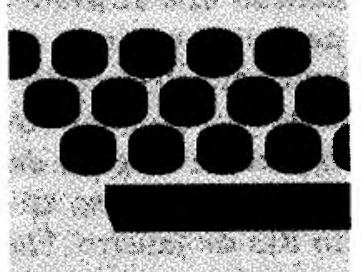

ARTIGO

Um estudo de diferentes estratégias de gestão do controle de qualidade sugere que a qualidade do produto depende da qualidade de vida dos trabalhadores.

A study of different quality control strategies suggests that the products quality depends on the workers quality of life.

\section{PALAVRAS-CHAVE:}

Controle de Qualidade, indús-

tria de alimentos, processo de

trabalho.

\section{KEY WORDS:}

Quality control, food proces-

sing industries, labour process.

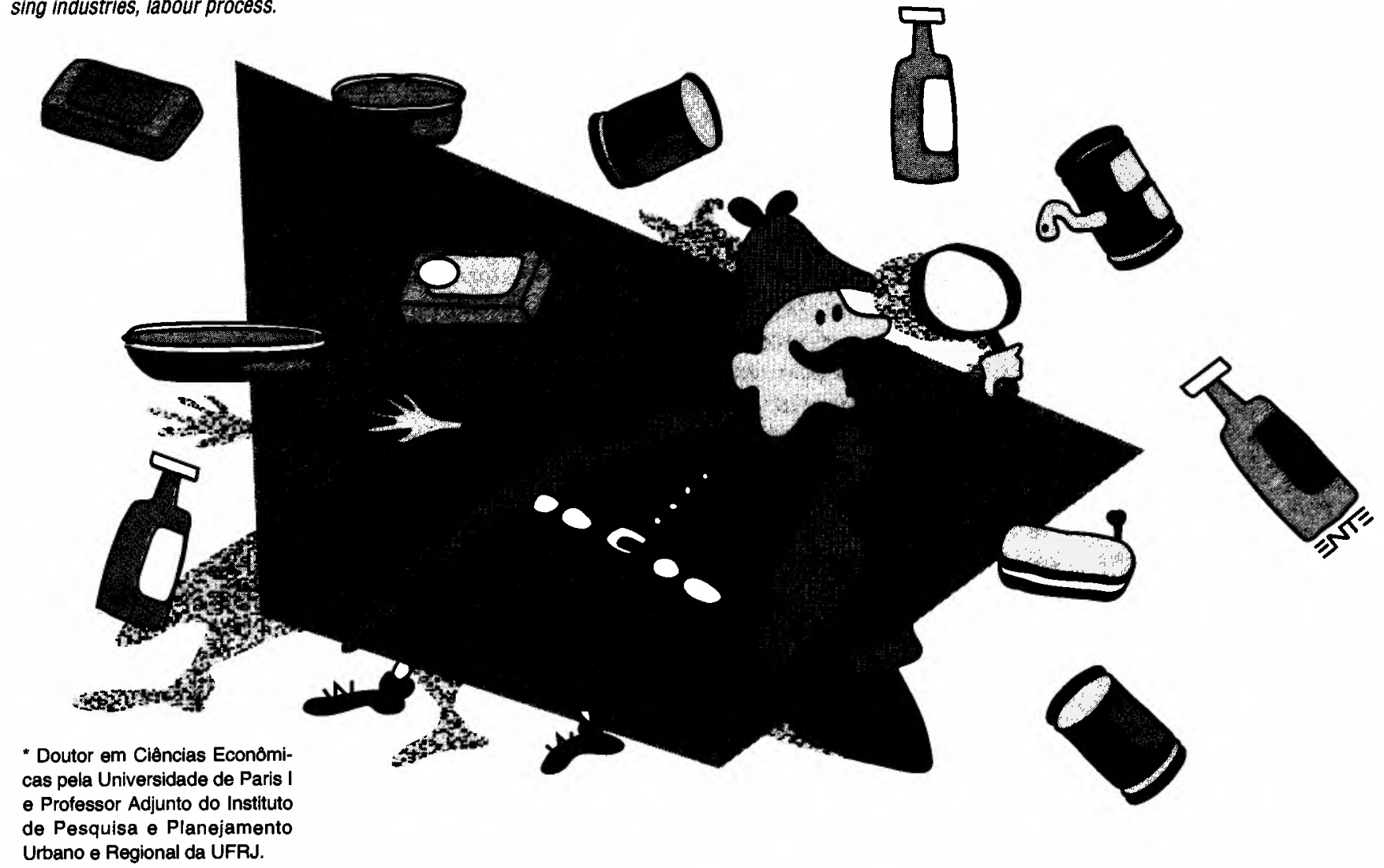


1. A pesquisa de campo que deu origem a este trabalho realizou-se no quadro de um projeto do Departamento Nacional do SENAI, tendo contemplado duas empresas de processamento de carnes, duas empresas produtoras de conservas de frutas e lequmes, uma empresa de beneticiamento e produçāo de de rivados de leite, uma empresa produtora de alimentos formulados, uma empresa produtora de massas, embutidos e alimentos formulados, uma industria de condimentos, uma empresa produtora de farinhas de geléias e um laboratório de controle de qualidade pertencente a uma grande rede distribuidora de alimentos e destinado a analisar a produção das unidades panificadoras da rede e os demais produtos industriais comercializados em seus estabelecimentos de distribuiçāo.
Os estudos sobre as relações estabelecidas entre as práticas de trabalho e as técnicas industriais tenderam, até aqui, a privilegiar a análise dos mecanismos pelos quais a valorização dos capitais condiciona a introdução periódica de novos modos de organização do trabalho fabril. Os objetivos de aceleração da velocidade de rotação do capital e, conseqüentemente, de geração crescente de valor por unidade de capital investido são evocados correntemente para explicar a busca de redução dos tempos globais de produção e de eliminação dos tempos mortos de trabalho. Há pouco entendimento, porém, sobre a natureza dos condicionamentos que podem exercer, sobre o trabalho industrial, os atributos qualitativos da mercadoria, elementos constitutivos do que a Economia Política chamou de valor de uso. É preciso reconhecer que o objetivo de obtenção das formas úteis da mercadoria condiciona, também, a organização do trabalho na fábrica. Este objetivo pode inclusive impor limites à reestruturação do processo de trabalho para fins de redução dos tempos globais de produção, no caso de tal reestruturação comprometer significativamente a qualidade do produto.

Sabe-se que o processo tendencial de fragmentação do trabalho em tarefas parcelares, que marcou a história das técnicas na maior parte dos segmentos industriais, subtraiu progressivamente ao trabalhador direto o controle sobre a configuração qualitativa do produto final. Promoveu-se, conseqüentemente, no contexto dos modernos sistemas industriais de produção em massa, o recurso compensatório a determinadas competências, destinadas a assegurar os atributos qualitativos dos produtos finais. Instituiu-se deste modo o campo de atividades do chamado controle de qualidade industrial.

A atividade do controle de qualidade tornou-se o veículo pelo qual assegurase ao produto os requisitos cujo não atendimento lende a refletir-se negativamente na realização mercantil da produção, pela incidência de lotes defeituosos, pelo comprometimento de imagens de marca e pela perda de partes de mercado.
No modo de operação do controle de qualidade, explicitam-se as diferentes formas de gestão empresarial do trabaTho com fins de obtenção dos atributos de uso requeridos para a mercadoria. $\mathrm{O}$ presente artigo pretende caracterizar distintas estratégias de gestão do controle de qualidade (CQ), a partir do estudo de dez empresas de processamento de alimentos no Estado do Rio de Janeiro. Ele tenta estabelecer o modo como, para além dos objetivos fundamentais de ge-

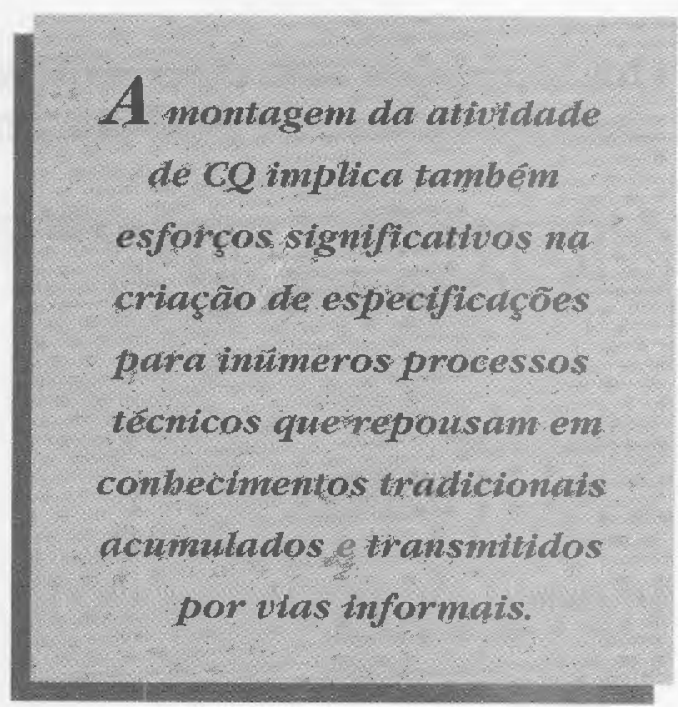

ração de valor, o processo de trabalho irrdustrial submete-se também a injunções provenientes da esfera da circulação de mercadorias e da natureza particular das formas úteis dos produtos. ${ }^{1}$

Ao caracterizar diferentes estratégias empresariais de controle de qualidade, o presente estudo não visa, porém, a produzir uma tipologia, mas apenas a identificar diferentes articulações possíveis entre a gestão das qualificações do trabalho e os objetivos de atribuição de determinados padrões qualitativos aos produtos.

\section{CONDICIONANTES TÉCNICOS E ECONÔMICOS DO CONTROLE DE QUALIDADE NA INDÚSTRIA DE ALIMENTOS}

A atividade de $C Q$ na indústria de alimentos defronta-se com inúmeras restrições de ordem técnica, notadamente pelo fator das matérias-primas biológicas predominantes nesta indústria apresentarem normalmente maiores dificuldades de especificação do que as substâncias 
químicas inorgânicas. Ao mesmo tempo, as variações sazonais da conformação dos produtos agrícolas condicionam consideravelmente a qualidade do produto acabado. A montagem da atividade de CQ implica também esforços significativos na criação de especificações para inúmeros processos técnicos que repousam em conhecimentos tradicionais acumulados e transmitidos por vias informais, que passam a requerer algum grau de formalização para efeito de estruturação de testes de qualidade. As mudanças técnicas, eventualmente introduzidas nos processos, também constituem fator de influência sobre a natureza do $C Q$ ao comprometer, ao menos temporariamente, a manutenção de especificações de qualidade suficientemente precisas. A multiciplidade de linhas de produção em operação em um mesmo estabelecimento fabril exerce um efeito também multiplicador sobre o rol de problemas técnicos do $C Q$, obrigando-o a conviver com produtos de vida de prateleira diferenciada, com fluxogramas de produção distintos e diferentes modelos de inspeção de qualidade em campo.

Às restrições de ordem técnica acima citadas, somam-se condicionantes econômicos que agem tanto no sentido do estímulo, como da limitação das atividades de CQ. Diversas variáveis, como custo de matéria-prima, custos salariais ou pressões sobre as margens de lucro, podem exercer efeitos diretos sobre a qualidade do produto, refletindo-se indiretamente sobre a atividade de CQ. A subdestinação de recursos para o treinamento de pessoal e para a manutenção de condições adequadas de higiene industrial estabelecem igualmente importantes condicionamentos sobre as práticas de $\mathrm{CQ}$.

O grau de desenvolvimento do CQ reflete, em certa medida, os padrões de competição vigentes na indústria, podendo ocorrer o recurso à prática de controle mais rigoroso como instrumento da conquista de partes crescentes do mercado. Mas as práticas do $C Q$ podem responder também às condições de competição em vigor entre as grandes redes de distribuição de alimentos, que podem adotar estratégias de disseminação de critérios mais rigorosos de qualidade pa- ra contratos de fornecimento em grande escala. ${ }^{2} \mathrm{Em}$ ambos os casos, o aperfeiçoamento do CQ é acompanhado pela tendência à exclusão do mercado de um certo número de pequenas empresas impossibilitadas de arcar com os dispêndios de montagem de controles apropriados de qualidade - fenômeno verificado com clareza nos Estados Unidos, após a edição do Food Act de 1955, ou quando do fechamento recente de empresas de processamento de carnes da Europa, que viram-se incapacitadas a suportar repentinamente os novos custos decorrentes da definição das normas européias em matéria de higiene industrial de alimentos. ${ }^{3}$ Neste sentido, a própria determinação dos padrões legais de identidade dos produtos alimentares pode representar alternativamente, um encargo adicional dificilmente assimilável por pequenas empresas, ou a legitimação de eventuais vantagens monopolísticas de certos segmentos da indústria.

$\mathrm{Na}$ conjuntura brasileira recente, as atividades de $C Q$ viram-se consideravelmente afetadas por processos desencadeados pelo Plano de Estabilização Econômica de fevereiro de 1986. De um lado, a demanda por qualidade elevou-se acentuadamente através da crescente mobilização social dos consumidores, manifestada, notadamente, nas pressões exercidas sobre a rede distribuidora de alimentos ao longo do primeiro semestre de 1986. Dadas as dificuldades temporariamente encontradas para que fosse empreendida a competição pelos preços, assumiu maior peso, em certos períodos e em determinados mercados, o mecanismo da competição pela qualidade e pela diferenciação do produto. Em oposição a tais fatores de estímulo ao $C Q$, o incremento do consumo das famílias, juntamente com a expansão dos mercados dos programas públicos de suplementação alimentar, ocasionaram uma aceleração dos ritmos de produção que não se revelaram, por vezes, compatíveis com a manutenção dos padrões de qualidades previstos. Foram suprimidas etapas essenciais do processo produtivo, como por exemplo, a de repouso do produto na fabricação de farinhas, medida que comprometeu seriamente as capacidades de ligamento das massas em etapas ulterio-
2. As grandes empresas de distribuição de alimentos, quando não integram verticalmente as atividades de produção, podem, por certo, exercer uma pressão significativa à elevação dos padrōes de qualidade dos produtos junto a seus fornecedores. Quando há, porém, a integração vertical da produção à comercialização, e a conseqüente distribuição da produção própria, pode ocorrer efeito inverso. com a execução do chamado "controle tolerante" sobre seus próprios produtos, dada a garantia de sua distribuição, isenta de competição, pela rede de comercialização da empresa.

3. Conforme Revue Technique de l'industrie Alimentaire, $n$. 343.11/25-3-1985. 
res do processamento. A própria qualidade da matéria-prima e dos insumos, dados os ritmos de crescimento da demanda e a insuficiência crescente da oferta, tendeu a decair, comprometendo conseqüentemente a qualidade dos produtos acabados.

O comportamento conjuntural da qualidade do produto alimentar submete-se, portanto, a uma variedade de injunções econômicas, sociais e jurídicas que influenciam o cálculo econômico que, em última instância, determina a adoção de práticas mais ou menos rigorosas de controle de qualidade. Dada a ação das variáveis conjunturais condicionantes da qualidade do produto e o modo de inserção das empresas no processo competitivo, a atividade de CQ pode assumir maior ou menor identidade e autonomia face às atividades correntes de processamento.

A observação do modo concreto de estruturação do $\mathrm{CQ}$ indica a existência de dois níveis possíveis de intervenção do controle. Um primeiro nível de intervenção corresponde a certas operações correntes de processamento, cuja execução é atribuída aos próprios trabalhadores do $C Q$, dada a interface destas operações com práticas laboratoriais ou de seleção e classificação de materiais. Estas ações confundem-se, portanto, com as práticas produtivas correntes, e são claramente distinguíveis das ações explícitas de controle propriamente dito exercido sobre a produção. Neste primeiro grupo de operações, incluem-se aquelas ligadas ao conceito de qualidade especificamente industrial, como a seleção de matérias-primas apropriadas ao processo, a medição da consistência e $\mathrm{pH}$ adequados à concentração de uma geléia, o acompanhamento dos indicadores de densidade e acidez de legumes em fermentação em salmoura antes do envase etc. Um segundo nível de intervenção do $C Q$ corresponde às ações que se sobrepõem às operações correntes de processamento, respondendo pela otimização das condições da transformação industrial e pela elevação dos atributos de qualidade do produto. Incluem-se, neste campo de ação, as inspeções do modo operativo do trabalho industrial, a preservação do grau de inocuidade dos materiais empregados, assim como da integridade da estrutura físico-química do produto e da qualidade bacteriológica julgada compatível com a natureza do produto alimentar.

Dada a distinção acima explicitada, o grau de desenvolvimento do CQ é tanto maior quanto as empresas agregam às operações correntes do processamento, as práticas de inspeção de campo e análise laboratorial que compõem a área de atuação específica do controle dos atri- grau de desenvolvimento do cQ tem também por indicador o rigor na administração dos dados e no arquivamento de laudos analíticos, podendo comportar, em certos casos, até a informatização destes serviços. butos qualitativos do produto. Reconhece-se, então, o maior grau de desenvolvimento do $\mathrm{CQ}$ nos niveis de qualificação de sua equipe, na disposição de instrumental adequado, em seu caráter mais abrangente tendente a cobrir uma ampla gama de elemento e etapas do processo, desde a matéria-prima, os insumos, os serviços de água, os materiais de embalagem, as condições de higiene e sanitização, a limpeza e a funcionalidade das instalações, as condições de armazenagem e transporte, até o produto acabado. O grau de desenvolvimento do CQ tem também por indicador o rigor na administração dos dados e no arquivamento de laudos analíticos, podendo comportar, em certos casos, até a informatização destes serviços. Observa-se, por fim, a existência de unidades laboratoriais de análises físico-químicas e microbiológicas de rotina e, por vezes, unidades especializadas em algumas práticas específicas, como a dos laboratórios de análises ao recebimento da matéria-prima - 
quando há risco de fraude nos fornecimentos (a aguagem do leite, por exemplo), ou na devolução de produtos acabados, quando se quer acompanhar a vida de prateleira da mercadoria. Unidades laboratoriais especiais são também implantadas com vistas à realização mais intensificada de certas análises, quando os produtos são destinados a mercados dotados de exigências específicas, como os mercados de exportação.

O grau de desenvolvimento do $C Q$ corresponde, por certo, à disposição e à possibilidade técnico-financeira das empresas integrarem o processo de competição por via da qualidade do produto. Mas ele responde igualmente a um certo número de estímulos concretos provenientes das condições dos mercados, da evolução das relações sociais de consumo ou do advento de eventuais experiências traumáticas específicas à história de cada empresa, quando a qualidade insatisfatória coloca em risco a realização de contratos de fornecimento em grande escala. Nesta medida, o CQ é estimulado, em particular, junto às empresas que participam das licitações para fornecimento aos mercados institucionais - como o dos programas públicos de suplementação alimentar - devido à importância dos contratos e ao relativo rigor dos requisitos de qualidade colocados pelos órgãos contratantes. ${ }^{4}$ As empresas que destinam parte importante de sua produção aos mercados externos são também, por seu lado, incentivadas a aperfeiçoar suas técnicas de CQ, assim como as empresas que dependem das grandes redes de distribuição de alimentos que, dado o volume de suas compras, podem constituir, nos casos em que disponham de efetivos departamentos de CQ estruturados, pólos de irradiação da demanda por qualidade exercida pelos consumidores em direção aos produtores de alimentos.

$O$ aperfeiçoamento do $C Q$ depende também do grau de perecibilidade dos produtos e da percepção empresarial de que a atividade de controle pode representar importante redução das perdas e compressão líquida de custos. Constatase, por fim, que certas empresas dão impulso ao $C Q$ após atravessarem momentos difíceis, com o risco de perda de con- tratos volumosos ou a experiência de longas lutas contra processos de contaminação de instalações fabris. A demonstração da pertinência do $C Q$ na superação das crises e, conseqüentemente, na prevenção da reincidência eventual de crises semelhantes, resultam, via de regra, no fortalecimento do mesmo em termos de pessoal, qualificações, equipamentos, instalações e autonomia administrativa.

A racionalidade econômica preside, por certo, a decisão de implantação da atividade de CQ. Há, por um lado, um cálculo econômico evidente naquelas práticas de controle que confundem-se com as atividades correntes de processamento. No caso da seleção de matériasprimas, por exemplo, certas empresas contam com o CQ para elevar as margens beneficiárias de certos lotes, ordenando a entrada da matéria-prima em processamento segundo os distintos graus de maturação dos produtos agrícolas, de forma a evitar a ocorrência de perdas na estocagem, ou então comprando lotes de matéria-prima já madura a preços reduzidos, prevendo o seu processamento imediato. Também os esforços de otimização das condições de processamento respondem a um cálculo econômico no qual o CQ se inclui, favorecendo a elevação da vida de prateleira do produto, a redução das perdas e a conseqüente diminuição dos custos.

A rentabilidade final de um investimento em CQ pode advir dos ganhos de credibilidade do produto no mercado, assim como da consolidação de imagens de marca. $\mathrm{O}$ cálculo econômico deverá computar, sem dúvida, os elevados custos dos reagentes necessários aos testes de qualidade, bem como os custos de aquisição da instrumentação analítica e da formação ou contratação de pessoal qualificado. A própria decisão quanto à realização de determinadas análises responderá a cálculos gerenciais específicos como, por exemplo, o que afasta eventualmente a realização de análises microbiológicas, sob alegação de que uma sobrecarga de custos advém da defasagem entre o tempo global de processamento e o período de quarenta e oito horas necessário, em média, à obtenção de resultados em microbiologia. Em certos
4. Há que ressaltar, por certo, que este rigor não encontra, necessariamente, correspondência nas condições de distribuição, estocagem e preparo dos alimentos nos programas institucionais. 
casos, a natureza do produto e a estratégia de CQ não prescindirāo das análises microbiológicas, enfrentando então a defasagem temporal entre os resultados analíticos e o processamento, pela duplicação das análises mais longas por testes subsidiários e de resultado imediato (como o teste de azul de metileno aplicado ao leite pasteurizado).

Há, porém, situações que atribuem economicidade intrínseca às atividades de CQ: ao orientar a gestão racional de sanitização, por exemplo, explicita-se como o emprego excessivo de detergentes é prejudicial aos equipamentos, constituindo, simultaneamente, um elemento de sobrecusto e um fator limitativo da eficácia da higienização, posto que o emprego de detergentes em concentração incorreta reduz o poder descontaminante destes produtos. Neste caso, a ação de CQ contribui, ao mesmo tempo, para economizar material de sanitização, reduzir a corrosão dos equipamentos e elevar os níveis de eficiência da higienização.

Em resposta aos distintos fatores de estímulo ao desenvolvimento do $\mathrm{CQ}$, certas empresas sugerem a pretensão de expandir suas atividades de controle, seja diversificando-as na direção da pesquisa e desenvolvimento de novos produtos, seja reforçando a realização de certos testes físico-químicos, ou vislumbrando o ingresso na área das análises microbiológicas.

Mas uma observação mais rigorosa demonstra que o fortalecimento do $\mathrm{CQ}$ depende também das complexas relações estabelecidas entre a administração central da empresa, as gerências de produção e os Departamentos de Controle de Qualidade. Neste contexto, o Departamento de CQ é levado a legitimar-se junto à administração central da empresa, tentando explicitar a economicidade global de seus procedimentos, assim como os ganhos de credibilidade que eles podem propiciar à mesma. Face aos responsáveis pela produçāo, o Departamento de $C Q$ é levado, por vezes, a demonstrar a validade de seus resultados analíticos, buscando, em casos extremos, sua confirmação junto a órgãos externos à empresa, como laboratórios oficiais ou universitários. Em outros casos, o CQ torna mais freqüentes suas amostragens com o fim de reverter a eventual descrença da gerência da produção ou de tentar contornar a aparente incompatibilidade entre os parâmetros analíticos formais e as evidências fundadas no saber técnico tradicional dos responsáveis pela produção, quando estes expressam dificuldades no entendimento das análises. Enquanto rão se alcança o entendimento desejado junto aos responsáveis pela produção, é comum a fixação de especifi-

E m. resposta aos distintos fatores de estimulo do desenvolvimento do $\mathrm{CO}$ certas empresas sugerem a

pretensâo de expandir suas atividades de controle, diversificando-as na direça da pesquisa e desemvolvimento de novos produtos.

cações e padrões mais rígidos do que os realmente necessários - meio utililizado pelo CQ para, com margem de segurança, resguardar-se de eventuais desvios praticados no processo produtivo. Em síntese, face à condução geral do processo produtivo, o CQ e a Gerência de Produção engajam-se em um aparente confronto entre objetivos de qualidade e objetivos de volumes de produção, conflito cujo tratamento se traduz na adoção de distintas estratégias globais de controle de qualidade, que a seguir serão analisadas separadamente.

\section{ESTRATÉGIAS ALTERNATIVAS DE GESTÃO EMPRESARIAL DO PROCESSO DE TRABALHO \\ FACE AOS OBJETIVOS DE GARANTIA DAS FORMAS ÚTEIS DO PRODUTO ALIMENTAR}

Designamos aqui por estratégias de controle de qualidade os modos empresariais de organização do trabalho e de gestão das qualificações do trabalho com vistas à obtenção de atributos predeter- 
minados de uso das mercadorias. Tais estratégias resultam em distintos modos de integração das atividades explícitas de CQ no processo produtivo, considerando-se, em particular, os diferentes graus e tipos de identidade própria, atingidos por estas atividades frente às operações correntes de produção.

\section{Estratégias de controle autônomo de qualidade exercido sobre a produção}

O primeiro tipo de estratégia definese pelo fato das atividades de $C Q$ voltarem-se para o exercício de um efetivo controle sobre o processo produtivo. Observa-se, neste caso, a vinculação formal do $C Q$ à Direção Industrial e um grau de autonomia em face da Gerência de Produção suficiente para imprimir à rotina das práticas produtivas os preceitos requeridos para o alcance das especificações desejadas. Nestes casos, os conflitos potenciais entre os objetivos de qualidade e os de volume de produção tendem a ser institucionalizados e levados às instâncias diretoras quando não são, com sucesso, negociados entre as respectivas gerências. A autonomia do $\mathrm{CQ}$ permite, por certo, que ele exerça seu papel fiscalizador sobre as condições visíveis da produção, mas também que execute um acompanhamento dos parâmetros não aparentes dos processos físico-químicos e microbiológicos internos ao produto. Neste sentido, a exterioridade e autonomia do $\mathrm{CQ}$ face à Gerência de Produção não visam apenas a darlhe força administrativa, mas também maior eficácia funcional. Assim, pode o $\mathrm{CQ}$ apontar, a partir de uma observação externa, a incidência de práticas produtivas incorretas dificilmente percebidas pelos próprios trabalhadores de produção, posto que trazidas pela própria rotina repetitiva dos processos. Pode, igualmente, fazer face a circustâncias imprevistas, como no caso da detecção das causas de uma contaminação. Tende a exercitar-se também no enfrentamento de situações emergenciais, como o exemplifica a intervenção do $C Q$ na reformulação funcional e espacial de uma fábrica de laticínios, contaminada por ocasião das graves inundações ocorridas no sul do País em anos recentes. Nesta medida, passa o $\mathrm{CQ}$ a desempenhar não apenas um papel fiscalizador do processo produtivo visível - notadamente através da inspeção de campo - mas também de investigador permanente das condições não aparentes do processo, com o apoio essencial das práticas laboratoriais. E, para tanto, exemplar o caso em que longos meses de investigação foram necessários para a deteç̧ão de uma fonte de contaminação de uma fábrica de massas que só pôde ser desvendada quando o acaso levou a que fossem coletadas amostras em um momento não previsto do processo, revelando por esta via o foco originário do fenômeno. Em outro exemplo, a intensificação da coleta de amostras permitiu que se localizasse uma contaminação a partir do desgaste do material usado na pressão sobre as placas de um trocador de calor, desgaste este que fazia diminuir a vedação entre o produto e a água de resfriamento, permitindo a infiltração desta última no produto.

O $\mathrm{CQ}$ pode, nesta medida, vir a ser concebido como um centro depositário do saber técnico sobre o processo produtivo e sobre a operação global da planta. A superestimação de suas capacidades pode, porém, em alguns casos, projetar no $C Q$ atributos de excepcionalidade que tendem a ser reforçados por seu manejo dos processos não aparentes da microbiologia dos alimentos. Face à "magia" de um laboratório de $C Q$, podem manifestar-se, em conseqüência, episódios de requisição pouco discriminada de serviços. Mas, após a sensação vivenciada com as primeiras análises microbiológicas realizadas numa planta e a possível sobrecarga do laboratório com um leque excessivamente diversificado de solicitações, tende-se, normalmente, ao emprego mais racional das qualificações detidas pelo $C Q$, estabilizando-se as análises ao nível dos materiais, do produto pronto, dos serviços de água e dos pontos do processo em que se acrescenta algum elemento novo ao produto em curso de processamento.

As práticas do primeiro tipo de estratégia de $\mathrm{CQ}$ procuram a compatibilização entre a própria concepção das instalações fabris e os requisitos do controle. Quando tal não acontece, o $\mathrm{CQ}$ deve aprofundar-se no conhecimento do pro- 
cesso produtivo para adaptar-se gradualmente, e, por vezes, ao sabor das crises, ao desenho da planta, procurando retirar as atividades de CQ dos pontos mortos disponíveis na fábrica. Tais experiências adaptativas resultaram, em alguns casos, até em seguidas destruições e reconstruções de unidades produtivas, na busca de colocá-las ao abrigo dos agentes contaminantes pela revisão do desenho de áreas externas de movimentação, fluxos sanitários, sistemas de ventilação e condições ambientais em geral.

As estratégias de CQ exercidas sobre a produção não implicam necessariamente uma predominância das práticas laboratoriais. É possível a ocorrência de um CQ autônomo e forte, constituído, por razões de natureza do processo técnico, predominantemente pela inspeção de campo. Se no caso da predominância do laboratório, " $a$ inspeção de campo constitui os olhos do CQ, levantando suspeitas para a análise dos responsáveis pelo laboratório", no caso da predominância da inspeção de campo, "o laboratório faz as análises requeridas pelo $\mathrm{CQ}$ de campo". No primeiro caso, o saber técnico concentra-se no laboratório, que é responsável pela orientação da produção com o apoio dos inspetores de campo. No segundo caso, freqüentemente em razão do caráter tradicional dos processos, o saber técnico concentra-se na inspeção de campo, depositária das capacidades perceptivas básicas dos chamados "práticos" no reconhecimento sensorial das condições do processamento, com o recurso fundamental, mas delimitado, às práticas laboratoriais. Neste último caso, no entanto, os conceitos de CQ penetraram a própria produção, fazendo dos inspetores de campo seus agentes diferenciados e independentes face aos responsáveis pela produção.
Estratégias de controle de qualidade subordinado à produção com responsabilidade sobre as condições periféricas de produção

O segundo tipo de estratégia de $C Q$ é aquele em que o controle é concebido como um dos componentes do Departamento de Produção. Não há autonomia dos membros do $C Q$ face à produção, não existindo, portanto, nenhuma instância que exerça uma fiscalização sobre as operações da produção ou um acompanhamento sistemático das condições físico-químicas e microbiológicas do produto. Designa-se aqui por $C Q$, na verdade, o conjunto formado pelo laboratório e pelo corpo de encarregados de produção. A estes últimos atribui-se a incumbência de fazer o controle de qualidade de campo, reduzido de fato às próprias práticas de supervisão baseada em critérios visuais e olfativos que não são substancialmente alterados por conceitos sistematizados de controle de qualidade. Ao contrário do que se percebeu no primeiro tipo de estratégia, não são aqui os inspetores de campo "os olhos do CQ", mas "o CQ é que constitui os olhos da Gerência de Produção". Não havendo nenhuma equipe diferenciada de campo que exerça o controle sobre a produção, o CQ propriamente dito restringe-se, neste caso, simplesmente à unidade laboratorial que, nesta condição, "faz apenas o intercâmbio de informações com a Gerência de Produção", "assessorando a produção e atestando a qualidade do produto". De um lado, a equipe do laboratório nada conhece sobre as formulações, $e$, de outro, os encarregados de produção "vão ao laboratório buscar dados e não orientações". Além da realização de alguns testes físico-químicos - em parte, aqueles associados ao próprio rendimento industrial do processo, como a análise da força do 
gel utilizado na atribuição de consistência a geléias - ou a participação direta no processo produtivo, preparando salmouras ou caldas, por exemplo, o laboratório é responsabilizado diretamente apenas pelo controle da higiene e sanitização do ambiente e a deteç̧ão de roedores, ou de funções paralelas como a de planejar a alimentação dos trabalhadores. Neste tipo de estratégia, o CQ não é concebido como um centro difusor de saber técnico na empresa. Em certos casos, a carência destes pólos internos de competência é suprida pelo recurso a especialistas, eventualmente estrangeiros, que testam os produtos e repensam as práticas industriais da empresa, com vistas à melhoria das qualidades organolépticas do produto, buscando compensar assim a ausência de um CQ ativo e sistemático.

\section{Estratégia de controle de qualidade compensatório efetuado a posteriori}

O terceiro tipo de estratégia observado, caracteriza-se por privilegiar as ações corretivas em detrimento das ações preventivas de controle. Esta estratégia não comporta uma inspeção de campo autônoma, podendo não haver, por vezes, recurso a qualificações apropriadas nem mesmo ao nível da própria supervisão de produção, onde são encontráveis mecânicos ou contramestres têxteis encarregados da produção de geléias, por exemplo. Não cabe, neste caso, ao CQ a fiscalização da produção, nem tampouco a responsabilidade por condições periféricas e ambientais do processo, como higiene e sanitização das plantas. Por vezes, o $C Q$ não é formalizado em um Departamento e tampouco emite princípios a serem seguidos pelos trabalhadores da produção. No que diz respeito às práticas preventivas, faz-se " 0 mínimo necessário para o funcionamento da produção", procedendo-se ao chamado "controle tolerante", que fecha os olhos para certas impropriedades como, por exemplo, a má qualidade da matériaprima em épocas de crises de abastecimento. Costuma-se, neste caso, atribuirse ao $\mathrm{CQ}$ as funções laboratoriais constantes da seqüência produtiva e inerentes à própria natureza do produto, como as tarefas de reposição de sal, testagem de $\mathrm{pH}$ e densidade em processo de fermentação em salmoura. As análises de laboratório são, em geral, componentes do processamento corrente, incidindo sobre os atributos que fazem a própria identidade do produto, como consistência, concentração e transparência de geléias, por exemplo. Algumas análises são também justificadas exclusivamente quando é percebida alguma insuficiência nos exames visuais, como nas análises da acidez do azeite, por exemplo.

Ante a inexistência de normas apropriadas, restará ao $\mathrm{CQ}$ agir a posteriori tentando minorar os riscos de contaminação ou deterioração aceleradas do produto. Para tanto, recorre-se a uma elevação dos parâmetros técnicos dos procedimentos de conservação, como a pasteurização a $100^{\circ}$ em lugar dos $75^{\circ}$ requeridos, ou pela ampliação do tempo de passagem do produto pelo tratamento térmico. Pode-se também aduzir uma margem de segurança aos padrões de $\mathrm{pH}$. Além das práticas compensatórias nos procedimentos de conservação, recorre-se também ao armazenamento técnico, que permite observar, ao longo de alguns meses, conforme o caso, o estado de vácuo e descontaminação de um produto, prescrutando-se a ocorrência de defeitos nos processos de recravação através de sinais com vazamentos, estufamento ou mesmo explosão de latas.

O terceiro tipo de estratégia de CQ apóia-se, portanto, na adoção de práticas de conservação a altos parâmetros e de armazenagem técnica, que desempenham um papel compensatório face à inexistência de procedimentos apropriados de CQ sobre a produção, face à ausência de qualificações adequadas na produção e à inexistência de qualquer tipo de controle microbiológico dos alimentos.

\section{A QUALIFICAÇÃO DO TRABALHO E OS ATRIBUTOS QUALITATIVOS DO PRODUTO}

Dadas as estratégias até aqui delineadas, sobressai o papel central nelas desempenhado por dois fatores: a informação e a qualificação. A informação constitui a matéria-prima do controle, sejam elas informações obtidas através da inspeção de campo, sejam elas adquiridas por via das análises laboratoriais. A esto- 
cagem destas informações é essencial, por exemplo, para a racionalização do abastecimento em matérias-primas. Estas últimas podem, em certos casos particulares, atingir várias centenas de tipos diferentes de insumos, requerendo um acompanhamento cuidadoso das eventuais reincidências de determinados fornecedores em problemas de qualidade. $O$ cadastramento de amostras e o arquivamento dos laudos analíticos servem, por vezes, de arma de defesa da credibibilidade dos produtos, quando da ocorrência de alguma irregularidade após a entrega dos lotes. A pertinência e precisão dos dados do CQ serão, por outro lado, imprescindíveis para que se negocie a superação das freqüentes manifestações de empirismo por parte da Gerência de Produção.

A associação de idéias entre a prática do $\mathrm{CQ}$ e o sentido da visão é marcante em mais de uma das estratégias de $\mathrm{CQ}$ aqui mencionadas: o $C Q$ pode, em um caso, ser "o olho da Gerência de Produção", ou, em outro, a inspeção de campo ser vista como "o olho do CQ". O que está em jogo, portanto, em ambos os casos, é o objetivo da visão, ou seja, a natureza específica da informação procurada. O rigor no tratamento da informação será, por fim, essencial, pusto que dele dependerá a aceitação ou rejeição de lotes, a garantia de credibilidade das marcas e a prevenção da perda de partes de mercado.

A qualificação do trabalho surge, por sua vez, como uma dimensão conexa à informação, posto que ela implica determinado modo de distribuição da informação técnica entre os agentes da produção. Ela exprime, na realidade, a capacidade do coletivo de trabalhadores produzir e tratar as informações sobre o processo de trabalho na produção de alimentos. O manejo correto destas informações por parte dos trabalhadores será essencial para a prevenção dos riscos de contaminação e deterioração do produto alimentar. É, por esta razão, comum a vivência de situações de sobressalto por parte dos responsáveis pela produção, que temem afastar-se das plantas fabris, ainda que por curtos momentos, face aos riscos decorrentes dos consideráveis níveis de desqualificação da força de traba- lho na indústria de alimentos. Em certos casos, a possibilidade de realização de análises microbiológicas é completamente afastada pelo temor de que a desqualificação do pessoal de apoio resulte em processos inçontroláveis de infestação das fábricas.

A deficiente qualificação do trabalho é, com efeito, o nó górdio frente ao qual as empresas adotarão diferentes práticas, que podem ir do manejo do tempo de experiência na empresa como critério de alocação de trabalhadores às áreas mais

A associação de ideias entre a prática do CQ e o sentido da visão é marcante em mais de unia das estratégias de CQ aqui mencionadas: o CQ pode, em um caso, ser "o olbo da

Gerência de Produção", ou, em outro, a inspeçâa de campo ser vista como "o olbo do CQ".

sensíveis do processo produtivo, ao exercício de estrito controle sobre as condições de uso produtivo do corpo do trabalhador.

A capacidade das indústrias de alimentos assegurar padrões de qualidade adequados defronta-se, basicamente, às limitações do padrão específico do emprego vigente neste segmento industrial, caracterizado por níveis salariais e de escolaridade médios inferiores aos da indústria de transformação como um todo.

\section{A QUALIFICAÇÃO DO TRABALHO, O CQ E A ESPECIFICIDADE DO PRODUTO ALIMENTAR}

A natureza perecível da matéria-prima alimentar a torna extremamente sensível à ação de variáveis que lhe são externas, sejam elas provenientes do meio ambiente ou da ação do trabalho direto. Os processos de trabalho da indústria de alimentos têm, portanto, como núcleo, o 
manejo dos mecanismos não aparentes de degradação físico-química e de contaminação microbiológica das matériasprimas e produtos acabados. $\mathrm{O}$ bom andamento da produção, depende, conseqüentemente, do conhecimento e do controle que o coletivo de trabalho exerça sobre as circunstâncias que favorecem os processos de degradação e contaminação dos produtos. O saber técnico específico à indústria de alimentos repousa, portanto, na consciência de que existem processos de adulteração dos produtos que escapam à percepção sensorial primária, requerendo dos trabalhadores capacidades de abstração (no caso, a capacidade de conhecer eventos não visíveis) que não são exigidas nas atividades industriais alheias à ação danosa de microorganismos. Por outro lado, a necessidade de controle sobre os processos de degradação do produto ergue limites à simplificação de tarefas, bem como à fragmentação e distribuição do saber técnico entre os trabalhadores, pois, neste contexto, torna-se indispensável ao trabalhador direto conhecer a razão de ser das distintas operações e etapas do processo bem como de sua ordenação. O exercício do controle sobre os agentes contaminantes exige que os trabalhadores saibam porque respeitar as temperaturas apropriadas, manter a ordem seqüencial das operações, observar a dosagem das formulações, aplicar efetivamente os procedimentos de higiene e sanitização etc.

A qualificação do trabalho na indústria de alimentos tem, portanto, como requisito específico central, a consciência da existência do mundo não-aparente da microbiologia. Como a qualidade do produto alimentar depende da integridade físico-química e do estado microbiológico do mesmo, um alto nível de qualificação do conjunto dos trabalhadores afigura-se indispensável à garantia dos padrões qualitativos do produto.

No entanto, as estratégias de controle de qualidade observadas parecem prescindir de elevados níveis de qualificação distribuídos pelo conjunto da força de trabalho. Pelo contrário, dois outros tipos de procedimentos tendem a ser, alternativamente, adotados com a finalidade de obter requisitos de qualidade, sem recorrer à elevação dos níveis médios de qualificação do trabalho:

a. o primeiro tipo de procedimento consiste em combinar consideráveis investimentos em laboratórios com uma concentração de profissionais qualificados no setor de controle de qualidade. Neste caso, são mantidos os baixos níveis de qualificação e de salários dos trabalhadores da produção, compensando-se os eventuais procedimentos inadequados de processamento com um controle laboratorial $a$ posteriori do produto final e dos insumos intermediários. Tal alternativa resulta evidentemente onerosa, tanto pelo alto custo do instrumental analítico como pela permanência dos riscos de perda de produção. Mas ela é normalmente viabilizada nos segmentos industriais que produzem em grandes quantidades para mercados relativamente cativos como o dos programas institucionais de nutrição, onde a relativa estabilidade dos contratos de fornecimento em grande escala permite a diluição dos custos em capital fixo e recursos humanos para os laboratórios, bem como o das perdas eventuais de produção;

b. o segundo e mais difundido tipo de procedimento consiste em compensar os baixos níveis de qualificação do trabalho com o exercício de rigoroso controle sobre os corpos dos trabalhadores, seja sobre seus gestos produtivos, seja sobre seu estado de sanidade física. Em lugar de investir em formação profissional, opta-se aqui pela introdução de um rígido poder disciplinar, que tem por finalidade impedir a contaminação e a degradação do produto, buscando prevenir as eventuais perdas de produção.

Em ambos os procedimentos acima descritos, as empresas preferem empregar na produção trabalhadores pouco qualificados, e, portanto, desprovidos de conhecimentos técnicos suficientes sobre os processos microbiológicos. Por um lado, esta opção assenta-se fundamentalmente na recusa em alterar o padrão salarial característico da indústria de ali- 
mentos, onde os baixos salários associam-se ao emprego intensivo de mãode-obra feminina e recém-chegada do meio rural. Mas a preferência por trabalhadores pouco qualificados parece não restringir-se aos objetivos de compressão dos custos salariais, podendo explicar-se também pela natureza específica dos conhecimentos técnicos que caracterizam a formação profissional na área de alimentos, a saber, as noções de microbiologia.

\section{Por outro lado, em todas}

estas estratégias de conirole

de qualidade compatíveis com

batxos niveis médios de

quallificação dos trabalbadorès

da produgão, observa-se, em

maior ou menor grau, a

recurso a um poder disciplinar

exercido sobre o corpo destes

trabalbadores.

Com efeito, a furmação profissional na área da microbiologia consiste, basicamente, em dar visibilidade a processos biológicos não aparentes. Tal preceito pedagógico encerra, porém, a potencialidade simbólica de suscitar nos trabalhadores, por analogia, interrogações sobre dimensões, igualmente não aparentes, relativas aos processos sociais subjacentes à produção de mercadorias. Somos tentados a supor que, estando o conteúdo central da formação apoiado no desenvolvimento da consciência sobre processos biológicos não aparentes, esta consciência poderia vir a ser transferida pelos trabalhadores a outros aspectos do processo produtivo, favorecendo reinterpretações da própria organização social da produção. Em conseqüência, ao serem introduzidos no universo da microbiologia, os trabalhadores estariam não só melhor qualificando-se para o trabalho, mas também melhor habilitando-se a entender o processo social de produção em que se encontram inseridos. Neste caso, com particular relevância, a maior qualificação do trabalho resultaria em significativo fortalecimento do poder de barganha dos trabalhadores.

Por outro lado, em todas estas estratégias de controle de qualidade compatíveis com baixos níveis médios de qualificação dos trabalhadores da produção, observa-se, em maior ou menor grau, o recurso a um poder disciplinar exercido sobre o corpo destes trabalhadores. Tal poder exerce-se, primeiramente, pela delimitação de um conjunto de atitudes e gestos considerados impróprios ao espaço de produção, como o ato de coçarse, tocar os cabelos, espirrar etc. Este tipo de disciplina pode estender-se também a um controle sobre o estado de higiene corporal e sanidade física dos trabalhadores. Independentemente de seus gestos produtivos, o próprio corpo do trabalhador torna-se, então, objeto de exames para a detecção de lesōes cutâneas ou de eventuais doenças infectocontagiosas. Em ambos os casos, o instrumento do controle sobre os corpos dos trabalhadores é a vigilância. O próprio discurso gerencial insiste em que a inspeção de campo é o "olho do controle de qualidade" ou que "o controle de qualidade é o olho da gerência de produção". Este olhar, tendo por fim condicionar a constituição do corpo do trabalhador em força de trabalho, exerce minucioso controle sobre as operaçóes e gestos dos trabalhadores no espaço produtivo, inscrevendo-se, de certo modo, no paradigma da visibilidade total dos corpos idealizado no Panopticon de Bentham.

Mas o poder disciplinador dos corpos dos trabalhadores pode também estender sua ação ao nivel das condições de higiene e sanidade vigentes fora do espaço produtivo. Neste caso, não é mais a vigilância o instrumento do controle, mas a intervenção direta exemplificada na adoçāo do banho obrigatório para todos os trabalhadores ao início de cada jornada de trabalho. Um tal procedimento consagra uma inequívoca ruptura entre o corpo produtivo e o corpo não produtivo dos trabalhadores, entre o valor de uso do corpo do trabalhador para o capital e suas qualidades externas ao espaço fabril, entre os requisitos de sani- 
dade para a produção de mercadorias e os requisitos de sanidade para a existência dos trabalhadores.

Ao substituir a qualificação do coletivo de trabalhadores pelo controle disciplinar sobre seus corpos, as empresas assumem, portanto, a dicotomia entre o corpo produtivo e o corpo improdutivo dos trabalhadores e vêm-se, conseqüentemente, às voltas com as duras realidades da existência dos trabalhadores fora do espaço fabril. E, assim, quase unânime o reconhecimento gerencial de que a grande limitação ao respeito às normas de higiene industrial na produção de alimentos encontra-se nas próprias condições de vida dos trabalhadores. Assinalam também os técnicos de controle de qualidade que é difícil haver higiene no local de trabalho quando năo há higiene no local de moradia, não só por carências educacionais, mas, antes de tudo, pela insuficiência das condições materiais de habitação, con- substanciadas na ausência ou precaridade dos serviços de água e esgoto. Ainda segundo estes técnicos, é preciso "que o trabalhador tenha uma vida saudável para dar continuidade a ela dentro do ambiente de trabalho". Evidencia-se, portanto, a contradição entre os requisitos de higiene industrial na produção de alimentos e os baixos padrões relativos de remuneração e, conseqüentemente, de habitação dos trabalhadores da produção. Elucidam-se, igualmente, os mecanismos pelos quais a obtenção dos atributos qualitativos das mercadorias passa não só pelas estratégias empresariais de gestão das qualificações no espaço fabril, mas também, e, no caso da indústria de alimentos, sobretudo - pelas próprias condições de existência dos trabalhadores. $O$ uso deste segmento industrial nos permite entender efetivamente como a qualidade do produto pode depender, antes de tudo, da qualidade de vida dos trabalhadores.

\section{BIBLIOGRAFIA SUPLEMENTAR}

- BLANCHFIELD, R. Good manufacturing practice in the food industry. Food, s.1., p. 47-9, Nov. 1985.

- CHAVES, J. B. Paes. Controle de qualidade para indústria de alimentos, principios gerais. Viçosa: Universidade Federal de Viçosa, $1980,80 \mathrm{p}$.

- CLARK, J. Food, drink and tabacco. Technological trends and employment; basic consumer goods. Sussex, SPRU, 1982, p. $80-124, v .1$

- DENIS, P. 0. et al. Food control in action. London: A.S.P., 1980.

- FENNEMA, 0. The food industry: charting a course to the year 2000. Food Technology, s. I., p. 47-62, Jan. 1983 :

- FRAZIER, W. C. Microbiologia de los alimentos. Zaragoza: Acribia, 1976, 512 p.

- GIDDEY, C. S., MENZI R. Impact du procédé technologique sur la qualité des ṕroduits alimentaires. Alimentation, s. I, v. 63, p. $59-61$, s.d.
- HERSCHOORFER, S. M. Quality control in the food industry. London: Academic Press, v. 1, 1967.

- KRAMER, A., TWIGG, B. Fundamentals of quality control for food industries, Westport: Avi Publishing, s.d.

- LUCAS, M. L. Le savoir-faire des industries agricoles et alimentaires face au progrès technique. Industries Agricoles et Alimentaires, s. J., v. 4, 1984:

- MARC, M. Les usines agro-alimentaires de demain; C'est dèjá Aujourd'hui Revue de L'industrie Alimentaire, s.l, v. $356, p$. 22-7, 4 a 18 de nov. 1985 .

- RATTNER, H. et al. Política e administração de tecnologia: um estudo comparativo da indústria de alimentos na América Latina, s.I., E. Blucher, 1983.

- VERGNET, P., VERGENET; M. Robotique et automation: quel choix pour les TAA? Revue de lindustrie Alimentaire. s. I., p. 34-7, nov./dez. 1985 . 